\title{
Risk Factors for Renal Function Impairment in Children with Meningomyelocele; a Single Center Study
}

\begin{tabular}{|c|c|c|}
\hline Author(s) & \multicolumn{2}{|c|}{ (D) Hülya Nalçacıoğlu1, (D) Demet Tekcan', (DÖzlem Aydoğ1 } \\
\hline Affiliation(s) & ${ }^{1}$ Ondokuz Mayis University Faculty & ic Nephrology Department, Samsun, Turkey \\
\hline $\begin{array}{c}\text { Article } \\
\text { Information }\end{array}$ & $\begin{array}{l}\text { Article Type: Original Articles } \\
\text { Article Group: Pediatric Nephrology }\end{array}$ & $\begin{array}{l}\text { Received: } 30.10 .2020 \\
\text { Accepted: } 14.11 .2020 \\
\text { Available Online: } 27.12 .2020\end{array}$ \\
\hline
\end{tabular}

Cite this article as: Nalçacıoğlu H, Tekcan D, Aydoğ Ö. Risk Factors for Renal Function Impairment in Children with Meningomyelocele; a Single Center Study. J Pediatr Acad 2020; 1: 86-89.

\section{Abstract}

Chronic kidney disease and its complications are among the most frequent cause of morbidity and mortality in patients with meningomyelocele. In this study, we aimed to determine the risk factors leading to chronic kidney disease progression in these patients.Fifty patients with meningomyelocele were analyzed retrospectively. Age, gender, follow-up period, serum creatinine, glomerular filtration rate, vesicoureteral reflux (VUR), initial urodynamic findings and initiation time of clean intermittent catheterization $(\mathrm{CIC})$ were noted. The progression of Chronic kidney disease (CKD) was evaluated by DMSA renal scintigraphy, changes in serum creatinine (Screa), and glomerular filtration rate (GFR). 30 of the 50 patients were included in the study. VUR was detected in $63 \%$ of the patients, and scar was detected in $83 \%$ by renal scintigraphy. The median value of Screa was $0.5 \mathrm{mg} / \mathrm{dl}$ in admission, while the median Screa was $1.02 \mathrm{mg} / \mathrm{dl}$ (min-max: 0.27-5) at the last visit and the difference was statistically significant $(p=0.001)$. A statistically significant was found between CKD progression and GFR in admission $(p=0.001), C l C$ onset age $(p=0.03)$, degree of VUR $(p=0.046)$, presence of renal scar $(p=0.002)$. It was shown that delay in admission ( $p=0.011$; OR 1.36; $\mathrm{Cl} 1.07-1.73$ ) and low GFR in admission ( $p=0.036$ OR $0.915 \mathrm{Cl} 0.842-0.994)$ were the most important risk factors. In our study, it was shown that delay in neurogenic bladder treatment, delay in the initiation of CIC, and low GFR at admission were important risk factors for the progression of CKD in children with meningomyelocele. Therefore, we aimed to emphasize the importance of regular follow-up of these children in Pediatric Nephrology Clinics from the neonatal period.

Keywords: Meningomyelocele, chronic kidney disease, risk factors

Correspondence: Hülya Nalçacıoğlu, Ondokuz Mayis University Faculty of Medicine, Pediatric Nephrology Department, Samsun, Turkey

E-mail: hulyanalcacoglu@hotmail.com 


\section{Introduction}

Neural tube defects are the most common pathology in the neurogenic bladder etiology in children and are responsible for $90 \%$ of cases. ${ }^{1-2}$ Spinal cord injury is a dynamic process that starts from the antenatal period and continues in postnatal life and is affected by many factors. All these problems result from the bladder's inability to perform its storage and emptying function properly, secondary to the deterioration of bladder innervation. In the urodynamic evaluation, an increase in detrusor filling pressures, detrusor sphincter dyssynergia, and high discharge or leakage pressures are determined. Upper urinary system dysfunction may develop over time in more than half of the children who are not treated. ${ }^{1-5}$

Children with meningomyelocele are generally born with normal upper urinary tract, but are at a high risk of chronic kidney disease (CKD) secondary to poor bladder dynamics. ${ }^{2-4}$ Only $5 \%$ of cases can urinate spontaneously. Therefore, almost all patients should be evaluated by predicting that they have a neurogenic bladder. The most common complications in patients with meningomyelocele are vesicoureteral reflux (VUR) secondary to neurogenic bladder, the development and progression of CKD with the development of renal parenchymal damage. ${ }^{4-7}$ Early detection of and prevention of renal scar with correct treatment result in renal preservation and a safe method of management. ${ }^{7-9}$

In this study, we aimed to determine the risk factors leading to CKD progression in children with meningomyelocele.

\section{Material and Method}

Fifty patients diagnosed with meningomyelocele were included in this study. A detailed history was taken from all patients, and physical examinations, including neurological examination were performed. Age, gender, time of follow-up, serum creatinine and GFR both at admission and last visit, urinary Ultrasonography (USG), Voiding Cystourethrogram (VCUG), DMSA renal scintigraphy and urodynamics reports, initiation time of clean intermittent catheterization $(\mathrm{CIC})$ were recorded. Renal function was evaluated by urinary USG, Screa with creatinine clearance calculated by the Schwartz formula ${ }^{10}$, and DMSA scan.

The Ethical Committee of Ondokuz Mayis University, Faculty of Medicine, approved this study (number: 220664). All the procedures in this work were in accordance with the ethical standards of the institutional research committee and with the 1964 Helsinki declaration and its later amendments or comparable ethical standards.

\section{Statistical Analysis}

Statistical Packages for the Social Sciences (SPSS) version 24 was used for statistical analysis. Mean, standard deviation, lowest, highest, median, ratio, and frequency values were used in the data's descriptive statistics. The distribution of variables was checked with the Kolmogorov Smirnov test. In quantitative data analysis,

the t-test was used for parametric distributed data, and the Many-Whitney $U$ test was used for non-parametric data. A Chi-square test was used to analyze qualitative data, and the Fischer test was used when test conditions were not provided. Pearson and Spearman correlation analysis was used for correlation analysis.

\section{Results}

\section{lights}

- Spina bifida is the most common cause of neuropathic bladder

of these patients prevent negati outcome of neurogenic bladder and prove both the survival and quality patients, and scar was detected in $83 \%$ by DMSA scan. $82.3 \%$ patients had bilateral grade $\checkmark$ VUR. The median Screa was $0.5 \mathrm{mg} / \mathrm{dl}$ (min-max: 0.17-1.7) at time of admission, while the median Screa was $1.02 \mathrm{mg} / \mathrm{dl}$ (min-max: 0.27-5) at the last visit. The difference was statistically significant $(p=0.001)$.

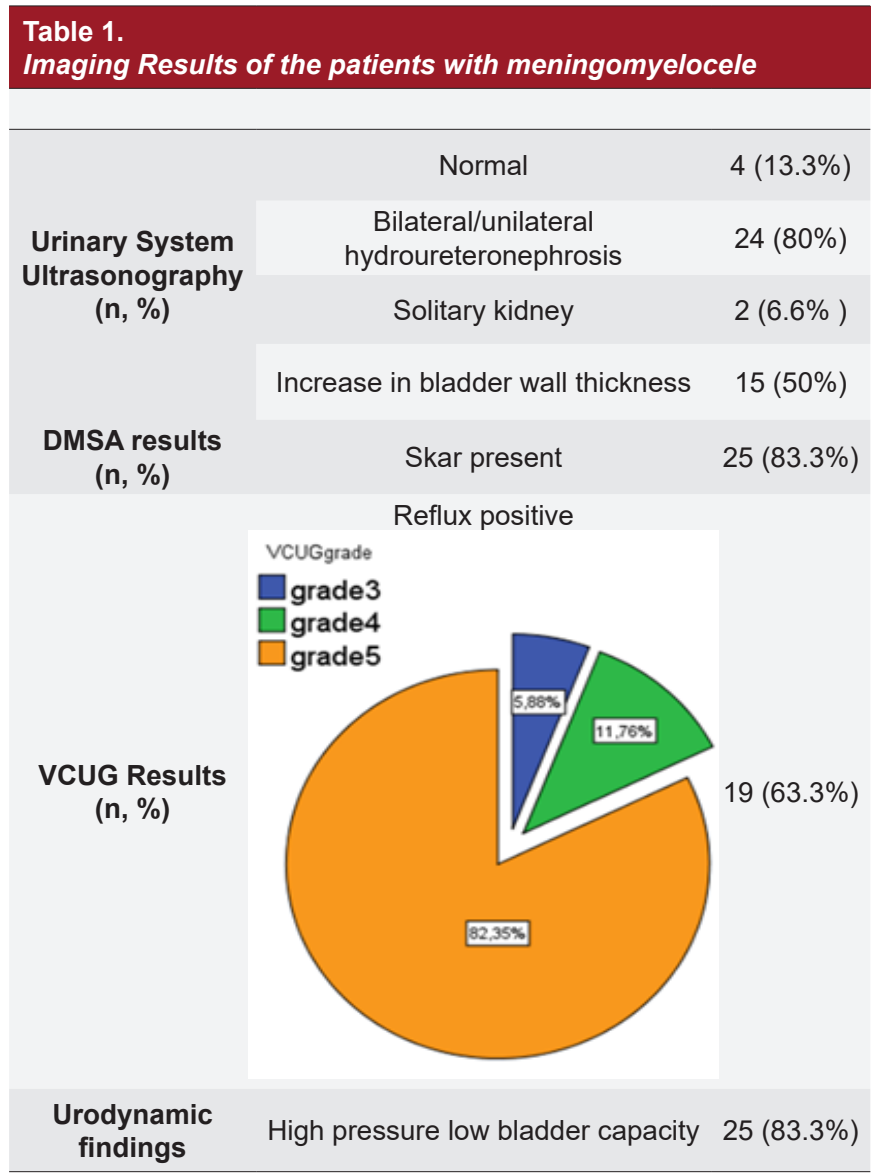

The median GFR was $66 \mathrm{ml} / \mathrm{min}$ (min-max: 12-178 ml/ $\mathrm{min}$ ) at time of admission, the median GFR was $51 \mathrm{ml} / \mathrm{min}$ (min-max: 10-221 $\mathrm{ml} / \mathrm{min}$ ) at the last visit. There was no statistically significant $(p=0.657)$. Laboratory results of the patients are given in Table 2. The median age at the initial time of $\mathrm{CIC}$ was four years ( 2 months- 16 years). 
Table 2

Laboratory results of patients

\begin{tabular}{lccc}
\hline & Admission & Last follow -up & $\mathbf{p}$ \\
\hline $\begin{array}{l}\text { Plasma Creatinine } \\
\text { mg/dl }\end{array}$ & 0.5 & 1.02 & 0.001 \\
GFR (ml/min) & 66 & 51 & \\
CKD, stage n (\%) & & & \\
Stage I & $6(22.2)$ & $10(34.5)$ & \\
Stage II & $9(33.3)$ & $2(6.9)$ & 0.284 \\
Stage III & $6(22.2)$ & $9(31)$ & \\
Stage IV & $5(18.5)$ & $5(17.2)$ & \\
Stage V & $1(3.7)$ & $3(10.3)$ & \\
\hline
\end{tabular}

There was statistically significant difference was found between CKD progression and admission GFR $(p=0.001)$, initial age of CIC $(p=0.03)$, VUR degree $(p=0.046)$ and presence of renal scar in initial DMSA $(p=0.002)$. There was no significance between recurrent UTI $(p=0.98)$ and CKD progression (Figure 1) (Figure 2).

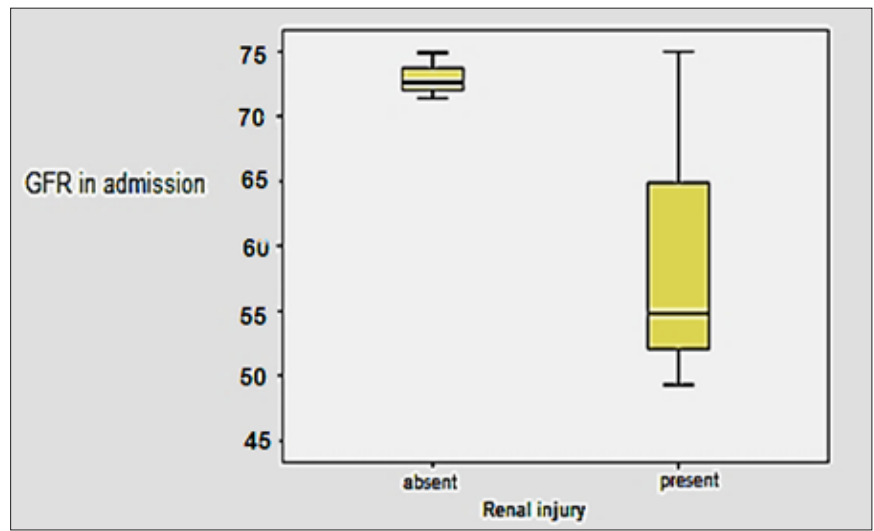

Figure 1. Relationship between chronic kidney injury and reference glomerular filtration rate

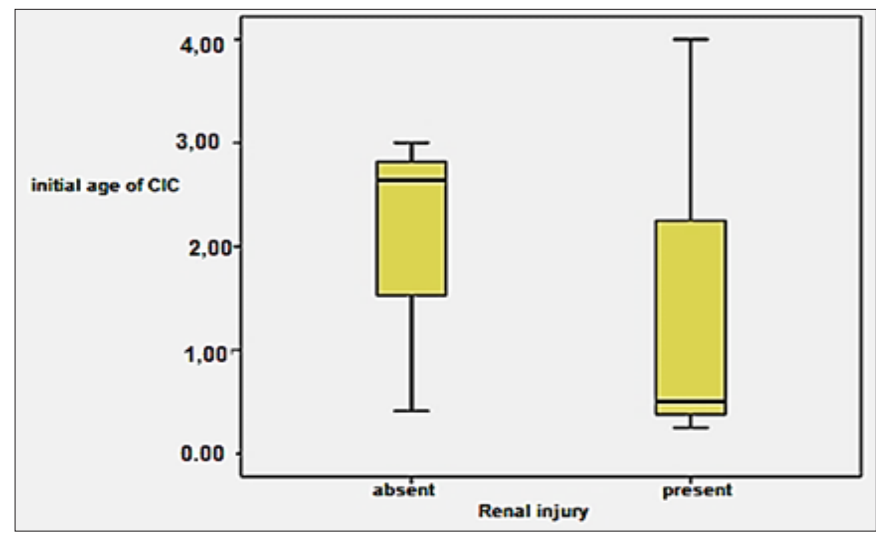

Figure 2. Relationship between chronic kidney injury and clean intermittent catheterization onset age

It was shown that delay in $\mathrm{CIC}(\mathrm{p}=0.011 ; \mathrm{OR} 1.36 ; \mathrm{Cl}$ 1.07-1.73) and low GFR at the time of admission $(p=0.036$ OR $0.915 \mathrm{Cl} 0.842-0.994$ ) were the most important risk factors.

\section{Discussion}

The development of kidney damage is the most important problem affecting life in meningomyelocele cases. Most children with meningomyelocele are born with a normal upper urinary system. ${ }^{11}$ However, it is expected that upper urinary system changes which start within the first six months of life due to the onset of bladder dysfunction. About $10-30 \%$ of children are born with the evidence of upper urinary tract pathology and increases to about $50 \%$ by the age of five..$^{12}$ Recent reports suggest that early detection of the pathology and follow-up with proper treatment result in excellent renal preservation and a safe method of management. ${ }^{12-14}$

Several factors may contribute to the severity of renal scarring. In this study, these factors included high-grade VUR, older age, low GFR at admission, late initial age of CIC. In our study, 25 (83.3\%) of 30 children had renal parenchymal damage. The cause of higher incidence of renal damage in our study could be explained by the delay in proper management, poor socio-economic background resulting in non-compliance issues, or the lack of adequate medical follow-up or management, including early diagnosis and treatment could also have contributed to the worse outcome in these patients. We emphasized the necessity of early proper treatment and referral which is still a problem in some areas.

This study revealed that, 19 (63.3\%) patients had VUR, and a significant relationship was found between the development of kidney damage and VUR. VUR was reported with a frequency of $15-50 \%$ in children with SD..$^{15}$ This finding is well defined to have negative effects on renal function in this patient group. ${ }^{16,17}$

Vesicoureteral reflux treatment is a controversial issue in meningomyelocele patients. Klose et al. ${ }^{18}$ reported that $92 \%$ of VUR decreased with only CIC. According to Sillen et al. ${ }^{19}$ no significant relationship was found between the regression of VUR in children with isolated high-grade reflux without spinal pathology and neurogenic bladder treatment in infancy. This suggests that reflux may not only be due to bladder dysfunction in cases with spinal pathology, and accompanying ureterovesical junction insufficiency may also play a role in VUR. This should be supported by larger and homogeneous patient groups. VUR treatment in children with the neurogenic bladder is so controversial in the literature because the groups are not homogeneous enough, and the number of patients in the series is insufficient to establish followup protocols. In our study group, we found a significant relationship between progression of kidney damage and high-grade reflux. As a result, we recommend that their kidney functions should follow up closely and choose the treatment in patients with high-grade reflux and congenital neuropathic bladder. Prediction of patients who are resistant to conservative management of VUR with $\mathrm{CIC}$, anticholinergic drugs and surgery may also prevent prolonged risk of renal damage.

In children with meningomyelocele, urodynamic findings provide important information about lower urinary tract dysfunction. Although multiple parameters are obtained in urodynamics according to the findings of the detrusor muscle and external sphincter activities, detrusor leak 
point pressure (DLPP) of $40 \mathrm{cmH}_{2} \mathrm{O}$ and above is the most important urodynamic parameter stated as a risk for upper urinary tract damage. ${ }^{20}$ We found that delay in admission and low GFR at admission were the most important risk factors for kidney damage development. Early investigation and management of neurogenic bladder are crucial to protect the kidneys. Early $\mathrm{CIC}$ is one of the most important factors in preventing kidney damage. Özel et al. ${ }^{21}$ reported that the risk of developing kidney damage increased when neurogenic bladder treatment was delayed. Dik et al. ${ }^{22}$ reported that they could reduce the development of kidney damage to $2.1 \%$ with early $\mathrm{CIC}$, antimuscarinic, and prophylaxis treatment immediately after birth in a study group of 144 patients.

\section{Conclusion}

In our study, in neurogenic bladder treatment, we found that delay in the initiation of CIC and low GFR at admission were important risk factors for the progression of CKD in children with meningomyelocele. There is a need for more awareness about the importance of starting proactive treatment to prevent renal damage of these children.

Acknowledgements: This study was accepted as a oral poster the $6^{\text {th }}$ Anniversary Meeting of the EPA, February 27-29 2019, Kayseri

Author Contributions: All of the authors declare that they have all participated in the design, execution, and analysis of the paper, and that they have approved the final version.

Conflict of Interest: The authors have no conflict of interest to declare.

Ethics Committee Approval: The Ethical Committee of Ondokuz Mayis University, Faculty of Medicine, approved this study(number: 220-664).

Financial Disclosure: The authors declared that this study has received no financial support.

Informed consent: Informed consent was obtained from all individual participants included in the study.

Peer-review: Externally peer-reviewed.

\section{References}

1. Ginsberg D. The epidemiology and pathophysiology of neurogenic bladder. Am J Manag Care 2013;19:191-196. [CrossRef]

2. Verpoorten C, Buyse GM. The neurogenic bladder: medical treatment. Pediatr Nephrol. 2008;23:717-725. [CrossRef]

3. Leonardo CR, Filgueiras MF, Vasconcelos MM, et al. Risk factors for renal scarring in children and adolescents with lower urinary tract dysfunction. Pediatr Nephrol. 2007;22:1891-1896. [CrossRef]
4. Bauer SB. Neurogenic bladder: etiology and assessment. Pediatr Nephrol. 2008;23:541-551. [CrossRef]

5. Snodgrass WT, Adams R. Initial urologic management of myelomeningocele. Urol Clin North Am. 2004;31:427-8. [CrossRef]

6. Wu HY, Baskin LS, Kogan BA. Neurogenic bladder dysfunction due to myelomeningocele: neonatal versus childhood treatment. $J$ Urol. 1997;157:2295-2297. [CrossRef]

7. Hopps CV, Kropp KA. Preservation of renal function in children with myelomeningocele managed with basic newborn evaluation and close followup. J Urol. 2003;169:305-308. [CrossRef]

8. de Jong TP, Chrzan R, Klijn AJ, Dik P. Treatment of the neurogenic bladder in spina bifida. Pediatr Nephrol. 2008;23:889-896. [CrossRef]

9. Geraniotis E, Koff SA, Enrile B. The prophylactic use of clean intermittent catheterization in the treatment of infants and young children with myelomeningocele and neurogenic bladder dysfunction. J Urol. 1988;139:85-86. [CrossRef]

10. Schwartz GJ, Haycock GB, Edelmann CM Jr, Spitzer A. A simple estimate of glomerular filtration rate in children derived from body length and plasma creatinine. Pediatrics. 1976;58:259-263. [CrossRef]

11. Rodríguez-Ruiz M, Somoza I, Curros-Mata N. Study of kidney damage in paediatric patients with neurogenic bladder and its relationship with the pattern of bladder function and treatment received. Actas Urol Esp. 2016;40:37-42. [CrossRef]

12. Kraus SR, Boone TB: Pediatric neurogenic bladder: etiology and diagnostic evaluation; in Gonzales ET, Bauer SB (eds): Pediatric Urology Practice. Baltimore, Lippincott Williams \& Wilkins, 1999, pp 365-381.

13. Edelstein RA, Bauer SB, Kelly MD, et al. The long-term urological response of neonates with myelodysplasia treated proactively with intermittent catheterization and anticholinergic therapy. $J$ Urol. 1995;154:1500-1504. [CrossRef]

14. Tarcan T, Bauer S, Olmedo E, Khoshbin S, Kelly M, Darbey M. Long-term followup of newborns with myelodysplasia and normal urodynamic findings: Is followup necessary?. J Urol. 2001;165:564-567. [CrossRef]

15. Flood HD, Ritchey ML, Bloom DA, Huang C, McGuire EJ. Outcome of reflux in children with myelodysplasia managed by bladder pressure monitoring. J Urol. 1994;152:1574-1577. [CrossRef]

16. Kurzrock EA, Polse S. Renal deterioration in myelodysplastic children: urodynamic evaluation and clinical correlates. J Urol. 1998;159:1657-1661. [CrossRef]

17. Seki N, Akazawa K, Senoh K, et al. An analysis of risk factors for upper urinary tract deterioration in patients with myelodysplasia. BJU Int. 1999;84:679-682. [CrossRef]

18. Klose AG, Sackett CK, Mesrobian HG. Management of children with myelodysplasia: urological alternatives. J Urol. 1990;144:1446-1449. [CrossRef]

19. Sillén U, Holmdahl G, Hellström AL, Sjöström S, Sölsnes E. Treatment of bladder dysfunction and high grade vesicoureteral reflux does not influence the spontaneous resolution rate. $J$ Urol. 2007;177:325-330. [CrossRef]

20. Woods C, Atwell JD. Vesico-ureteric reflux in the neuropathic bladder with particular reference to the development of renal scarring. Eur Urol. 1982;8:23-28. [CrossRef]

21. Ozel SK, Dokumcu Z, Akyildiz C, Avanoglu A, Ulman I. Factors affecting renal scar development in children with spina bifida. Urol Int. 2007;79:133-136. [CrossRef]

22. Dik P, Tsachouridis GD, Klijn AJ, Uiterwaal CS, de Jong TP. Detrusorectomy for neuropathic bladder in patients with spinal dysraphism. J Urol. 2003;170:1351-1354. [CrossRef] 